\title{
RANCANG BANGUN ALAT PENENTU CEPAT RAMBAT GELOMBANG BUNYI DI UDARA MENGGUNAKAN TABUNG IMPEDANSI
}

\author{
Sulanjari ${ }^{1}$ \\ ${ }^{1}$ Universitas Pamulang, Fakultas Teknik - Prodi Teknik Mesin, Tangsel - Banten \\ Email: sulanjari_skh@yahoo.co.id
}

Masuk : 4 Februari 2018

Direvisi : 24 Maret 2018

Disetujui : 4 April 2018

\begin{abstract}
Abstrak: Untuk membantu pemahaman materi-materi tentang gelombang khususnya gelombang bunyi yang tidak dapat dilihat dengan mata, maka perlu dirancang sebuah alat yang dapat memvisualisasikan gelombang bunyi sehingga menjadi lebih nyata dan lebih mudah untuk dimengerti. Tujuan dari penelitian ini adalah merancang alat dan menentukan cepat rambat bunyi di udara dengan menggunakan tabung impedansi. Kelayakan alat dapat dilihat dengan membandingkan nilai cepat rambat bunyi yang di peroleh dengan teori. Penelitian yang dilakukan menggunakan Audio Frequency Generator (AFG) sebagai sumber bunyi (frekuensi) yang dilewatkan pada tabung impedansi sehingga ditangkap microphone dan terbaca oleh software spectraLAB. Cepat rambat bunyi di udara dapat diperoleh dengan analisis fit linear pada software originPro8. Dengan variasi frekuensi $300 \mathrm{~Hz}-1000 \mathrm{~Hz}$ diperoleh nilai dari kecepatan rambat bunyi di udara pada suhu ruang

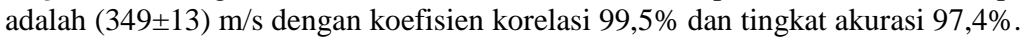

Kata kunci: Frekuensi, Cepat rambat bunyi, tabung impedansi, SpectraLab, OriginPro8

\begin{abstract}
To help the understanding of concept about the wave especially the sound waves that can not be seen directly with our eyes, accordingly it was necessary to design a tool that can visualize sound waves so that it becomes more real and easier to understand. The purpose of this research was to design an experimental tool and determine the speed of sound in the air by using impedance tube. The accuracy of research design can be determined by comparing the result of value of the speed of sound which was obtained with the theory. This research is conducted with using Audio Frequency Generator (AFG) as the source of sound (frequency) which is passed in impedance tube thus it can be detected by microphone and read by spectraLAB software. The value of the speed of sound can be obtained using linear fit analysis of originPro8 software. The result of reseach, we found that the value of the speed of sound in air at room temperature by varying the frequency value from $300 \mathrm{~Hz}$ to $1000 \mathrm{~Hz}$ was $(349 \pm 13) \mathrm{m} / \mathrm{s}$ with a value correlation coefficient of $99 \%$ and level of accuracy was $97,4 \%$.
\end{abstract}

Keyword: Frequency, the speed of sound, impedance tube, spectraLAB, originPro8

\section{PENDAHULUAN}

Ilmu yang mempelajari tentang gelombang termasuk juga didalammnya tentang bunyi menjadi bagian terpenting dalam mata kuliah Fisika dibeberapa jurusan ditingkat universitas. Dalam perkuliahan mahasiswa masih mengalami kesulitan untuk memahami ilmu tentang gelombang ini. Untuk membantu pemahaman mahasiswa materi-materi tentang gelombang khususnya gelombang bunyi yang tidak dapat dilihat dengan mata, maka perlu dirancang sebuah alat yang dapat memvisualisasikan gelombang bunyi sehingga menjadi lebih nyata dan lebih mudah untuk dimengerti[1]

Lubis melakukan penelitian tentang rancang bangun alat penentu kecepatan bunyi di udara berbasis instrumentasi[1]. Sumber bunyi berasal dari audio sinyal generator melalui loudspeaker dengan variasi frekuensi 1-12 kHz. Cepat rambat bunyi di udara yang didapat adalah $(340,33 \pm 1,92) \mathrm{m} / \mathrm{s}$. Nurkholis melakukan penelitian yang bertujuan untuk menentukan besarnya cepat rambat bunyi di udara menggunakan transduser ultrasonik berbasis mikrokontroler ATmega8535[2]. Dengan menggunakan sumber bunyi garputala nilai cepat rambat bunyi yang diperoleh adalah $(341 \pm 0,634) \mathrm{m} / \mathrm{s}$. Astuti melakukan penelitian rancang bangun alat eksperimen dan menentukan cepat rambat bunyi dalam medium udara dengan menggunakan metode Time of Flight (TOF) dan 
berbantuan software audacity[3]. Sumber bunyi yang digunakan adalah garputala. Nilai cepat rambat bunyi di udara yang diperoleh sebesar $(335,27 \pm 5,80) \mathrm{m} / \mathrm{s}$. Pada penelitian ini akan merancang alat untuk menentukan kecepatan bunyi di udara dengan menggunakan tabung impedansi dengan Audio Frequency Generator (AFG) sebagai sumber bunyi dengan variasi frekuensi 300, 400, 500, 600, 800, 900, $1000 \mathrm{~Hz}$.

Bunyi merupakan gelombang mekanis jenis longitudinal yang merambat dan sumbernya berupa benda yang bergetar. Bunyi bisa kita dengar sebab getaran benda sebagai sumber bunyi itu menggetarkan udara di sekitarnya dan melalui medium udara itu bunyi merambat sampai ke gendang telinga[4]. Pada hakikatnya kepekaan pendengaran telinga manusia sangat bergantung pada frekuensi bunyinya. Manusia hanya mampu mendengar bunyi yang frekuensinya antara $20 \mathrm{~s} / \mathrm{d} 20.000 \mathrm{~Hz}$ saja.[5]. Selama menjalar frekuensi bunyi itu tetap dan yang berubah hanyalah kelajuan dan panjang gelombangnya[4]. Pada zat cair dan padat, laju bunyi dalam medium padat lebih cepat dibandingkan dengan medium cair. Laju bunyi pada berbagai medium diberikan di tabel1. Nilai- nilai tersebut dalam beberapa hal bergantung pada temperatur dan tekanan[6]

Tabel1. Laju bunyi pada berbagai medium

\begin{tabular}{|l|l|l|}
\hline No & Medium & Laju $(\mathrm{m} / \mathrm{s})$ \\
\hline 1 & Udara & 340 \\
\hline 2 & Helium & 1005 \\
\hline 3 & Hidrogen & 1300 \\
\hline 4 & Air & 1440 \\
\hline 5 & Air Laut & 1560 \\
\hline
\end{tabular}

Jika frekuensi bisa ditentukan dan besarnya panjang gelombang bisa dicari maka nilai cepat rambat gelombang bunyi adalah:[7]

$$
v=f \lambda
$$

Dengan $v$ adalah cepat rambat bunyi, $f$ adalah frekuensi, dan $\lambda$ adalah panjang gelombang.

Dalam penelitian ini frekuensi adalah variabel kontrol dan panjang gelombangnya adalah variabel terikatnya. Sehingga persamaan menjadi:

$$
\lambda=v \frac{1}{f}
$$

Dengan menggunakan persamaan linear: $\quad Y=A+B X$

Sehingga $Y$ merupakan $\lambda, X$ adalah $\frac{1}{f}$ maka nilai B yang didapat merupakan $v$ (cepat rambat bunyi).

\section{METODOLOGI}

Alat dan bahan dalam penelitian ini adalah sebagai berikut: Tabung impedansi, berdiameter $10,5 \mathrm{~cm}$ panjang 4m. Audio Frequency Generator (AFG), sebagai sumber frekuensi. Amplifier, untuk penguatan frekuensi dari AFG agar dapat dideteksi microphone. Loudspeaker sebagai sumber bunyi. Condensor Microphone, sensor pendeteksi gelombang bunyi yang akan disalurkan ke komputer. Software SpectraLAB, untuk menganalisis spektrum sinyal suara yang terdeteksi oleh microphone. Software originPro 8 untuk menganalisis data. Batang A-B, untuk menggeser-geser Condensor Microphone.

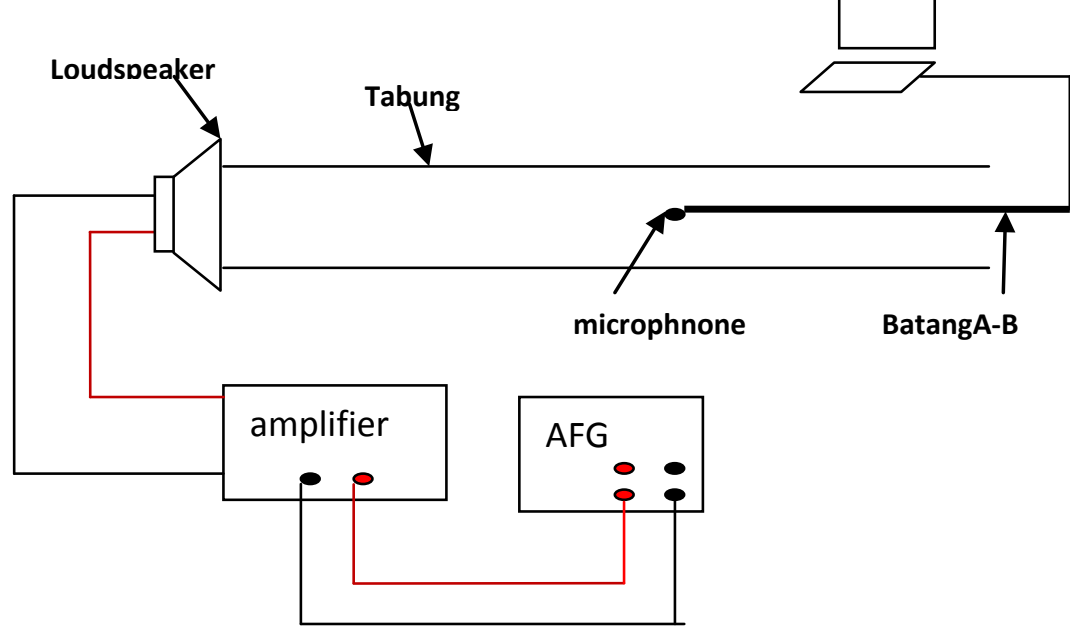


Gambar 1. Desain Penelitian

Adapun langkah-langkah penelitiannya sebagai berikut: Pertama mempersiapkan alat dan bahan. Kemudian membuat tabung impedansi dari paralon berdiameter 10,5 cm panjang $4 \mathrm{~m}$ diberi karpet didalamnya. Setelah merangkai alat dan bahan seperti pada Gambar1 pengambilan data bisa dilakukan dengan menyalakan AFG (mengatur pada frekuensi tertentu) dan Amplifier sehingga ada gelombang bunyi yang keluar melalui loudspeaker. Untuk mendeteksi amplitudo simpul perut gelombang bunyi pada tabung impedansi dengan cara menggerak-gerakkan batang A-B. Nilai setengah panjang gelombang bisa didapat dengan mengetahui jarak terjadinya simpul dan perut. Jika frekuensi dan panjang gelombang diketahui maka dapat menentukan cepat rambat bunyi.

\section{HASIL DAN PEMBAHASAN}

Hasil rekaman microphone setelah dihubungkan dengan PC akan terdeteksi nilai frekuensi dan amplitudo gelombang bunyi yang dapat dibaca melalui spectraLAB seperti pada gambar berikut:

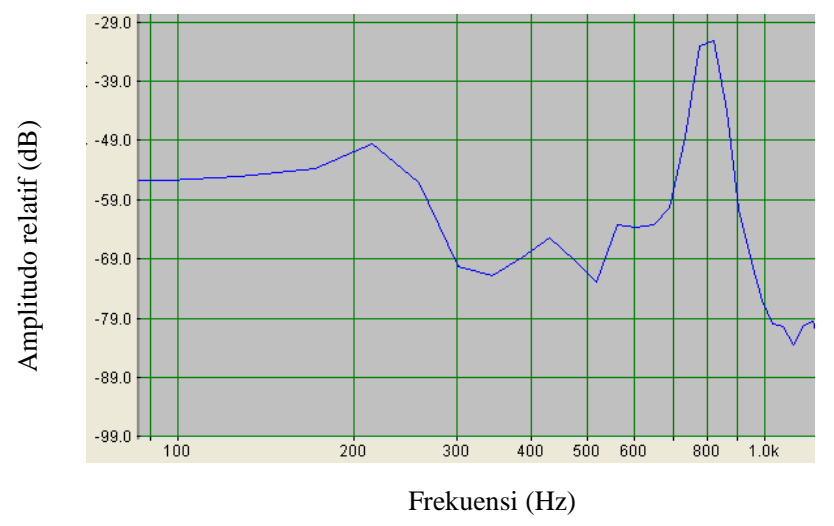

Gambar2. hasil rekaman spectraLAB pada frekuensi $800 \mathrm{~Hz}$

Dengan menggunakan spectraLAB ini kita bisa melihat amplitudo maksimal yang merupakan perut gelombang dan amplitudo minimal yang merupakan simpul gelombang. Jarak antar dua simpul merupakan panjang setengah gelombang. Sehingga panjang gelombang dapat ditentukan apabila kedua jarak simpul diketahui. Dengan memvariasikan 8 macam nilai frekuensi yaitu rentang $300 \mathrm{~Hz}-1000 \mathrm{~Hz}$ dengan interval $100 \mathrm{~Hz}$ diperoleh nilai panjang gelombang seperti Tabel 2 sebagai berikut:

Tabel 2. Frekuensi terhadap panjang gelombang

\begin{tabular}{|c|c|}
\hline $\begin{array}{c}\text { frekuensi } \\
(\mathrm{Hz})\end{array}$ & $\begin{array}{c}\text { Panjang gelombang } \\
(\mathrm{m})\end{array}$ \\
300 & 1.152 \\
\hline 400 & 0.808 \\
\hline 500 & 0.656 \\
\hline 600 & 0.604 \\
\hline 700 & 0.448 \\
\hline 800 & 0.412 \\
\hline 900 & 0.352 \\
\hline 1000 & 0.324 \\
\hline
\end{tabular}

Berdasarkan Tabel2 semakin besar nilai frekuensi maka nila panjang gelombangnya semakin kecil. Hal ini sesuai dengan teori bahwa pada cepat rambat gelombang yang tetap nilai panjang gelombang berbanding terbalik dengan frekuensinya. Kemudian data tersebut diolah dengan menggunakan software originPro 8 dengan analisis Fit Linear adalah sebagai berikut: 


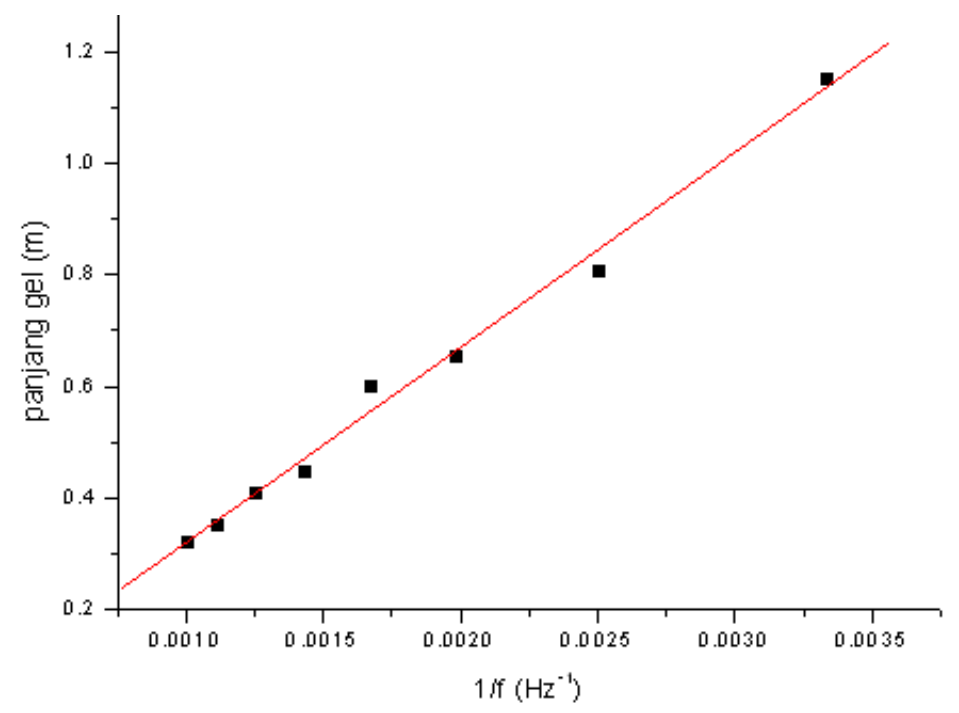

Gambar3. Grafik hubungan 1/f terhadap panjang gelombang bunyi

Dengan melihat grafik Gambar3 terlihat bahwa 1/f berbanding lurus dengan panjang gelombang bunyi, atau 1/f kita sebut sebagai periode (T) gelombang bunyi. Hal ini sesuai dengan teori bahwa semakin besar nilai periode semakin panjang juga nilai panjang gelombangnya.

Tabel3. Hasil analisis Fit Linear pada OriginPro 8

$$
\mathrm{Y}=\mathrm{A}+\mathrm{B} * \mathrm{X}
$$

\begin{tabular}{|c|c|c|c|}
\hline Parameter & & Value & Error \\
\hline A & & $-0,02817$ & 0,02568 \\
\hline B & & 349,32409 & 13,29223 \\
\hline $\mathrm{R}$ & SD & $\mathrm{N}$ & $\mathrm{P}$ \\
\hline 0,99568 & 0,02802 & 8 & $<0.0001$ \\
\hline
\end{tabular}

Pada Tabel3 hasil fit linear originPro 8 terlihat nilai B dan nilai Error (Ketidakpastian B) menunjukan nilai cepat rambat bunyi yang diperoleh adalah $(349 \pm 13) \mathrm{m} / \mathrm{s}$ Nilai yang diperoleh masih dalam rentang nilai kecepatan bunyi di udara pada referensi yaitu sebesar $340 \mathrm{~m} / \mathrm{s}$ dengan tingkat akurasi 97,4\% Nilai R menunjukkan nilai koefisien korelasi 99,5\% sehingga data yang diperoleh menggunakan alat ini bagus.

\section{KESIMPULAN}

Berdasarkan hasil penelitian, maka dapat diambil kesimpulan bahwa:

Dengan menggunakan alat ini diperoleh nilai kecepatan rambat bunyi di udara pada suhu ruang adalah

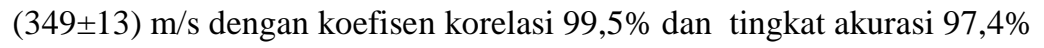




\section{DAFTAR PUSTAKA}

[1]. Lubis, Ashar Muda dan Lizalidiawati., Rancang bangun alat penentu kecepatan bunyi di udara berbasis instrumentasi, Gradien, 2005, 1, 10-15.

[2]. Nurkholis, Junaidi, dan A. Surtono., Rancang bangun sistem akuisisi data resonansi gelombang bunyi menggunakan transduser ultrasonik berbasisi mikrokontroler ATmega8535, Teori dan aplikasi fisika, 2014, 2,2.

[3]. Astuti, IAD., Pengembangan alat eksperimen cepat rambat bunyi dalam medium udara dengan menggunakan metode Time of Flight (TOF) dan berbantuan software audacity, UPEJ, 2016, 5, 3.

[4]. Priyambodo, Tri Kuncoro dan Jati, Bambang Murdaka Eka., 2008, Fisika dasar untuk mahasiswa ilmu komputer dan informatika, Yogyakarta, ANDI.

[5]. Soedojo, Peter., 2004, Fisika dasar, Yogyakarta, ANDI.

[6]. Giancoli, D. C., 2001, Fisika( 5 ed., Vol. 1), Jakarta, Erlangga.

[7]. Sears F.W., M. W. Zemansky, 1982, Fisika untuk Universitas 1, Bandung, Binacipta. 